\title{
Delineation of aquifers in basaltic hard rock terrain using vertical electrical soundings data
}

\author{
S N Rai*, S Thiagarajan, Y Ratna Kumari, V Anand Rao and A Manglik \\ CSIR - National Geophysical Research Institute, Hyderabad 500 00\%, India. \\ *Corresponding author. e-mail: snrai@ngri.res.in
}

The region under investigation for groundwater exploration is a part of the eastern fringe of Deccan traps in Kalmeshwar Taluk of Nagpur district. In this region, groundwater is the main source of water supply for drinking and irrigation purposes. Presently, the known source of groundwater is the upper weathered mantle in the depth range of 8-15 $\mathrm{m}$. This source of groundwater has been overexploited because of increasing demand of water supply and is unable to meet the present requirement. The present work deals with the delineation of new sources of groundwater at deeper levels concealed within and below the traps by using vertical electrical sounding surveys in order to meet the increasing demand of water supply.

\section{Introduction}

Nagpur is one of the 11 districts in Vidarbha region of Maharashtra, which is facing acute shortage of water supply for domestic and agricultural uses. This district is characterized with semi-arid climatic conditions. The normal annual rainfall over the district ranges from 1000 to $1200 \mathrm{~mm}$. It is minimum in the western parts around Katol and increases in the eastern direction (CGWB 2003). Rainfall is the main source of groundwater recharge. The region under investigation is located between $78^{\circ} 48^{\prime}$ to $78^{\circ} 53^{\prime} \mathrm{E}$ and $21^{\circ} 12^{\prime}$ to $21^{\circ} 15^{\prime} \mathrm{N}$ in northwest of Nagpur city at a distance of $\sim 25 \mathrm{~km}$. Figure 1(a) presents the location and geology of the investigated area, which is occupied by Deccan traps underneath a thin cover of alluvial soils of Recent to Quaternary period. Deccan traps consist of different layers of lava flows which are separated by sedimentary intertrappean beds deposited during the interval of two consecutive lava flows. Each lava flow is composed of vesicular basalt unit on top and compact basalt unit at the bottom. Intertrappeans together with the vesicular basalt units form groundwater potential zones between two compact basalt layers. At some places, clayey bole bed is found as intertrappeans. Massive basalt and clayey bole beds do not permit movement of groundwater and act as an impervious formation. Based on the presence of inliers of Gondwana sedimentary formation exposed in the Bazargaon reserve forest on the southern side and near Adasa on the northern side of the studied area, the probable extension of Gondwana formations below the traps is speculated. Presence of Gondwana sediments below the traps is confirmed by borewell drillings in the nearby regions of Jam river basin (Muralidharan et al. 1994), and at a site under Kotwalbardi village in Katol taluk (Rai et al. 2011). Stratigraphic sequence of this region is presented by Chakravarthi et al. (2007) after Mehta (1989).

The study area is a watershed having dense network of small channels as shown in figure 1(b).

Keywords. Deccan traps; hard rock; groundwater; resistivity model; vertical electrical soundings; intertrappean; Gondwana sediments. 
These channels are connected to two major channels. The first one passes through Pohi and Sonegaon villages and the second one emerges from the Kondhali reserved forest area and passes through Linga, Khairi and Upparwadhi as shown in figure 1(b). Both major channels flow from west to east and just before $52^{\circ} \mathrm{E}$ longitude, suddenly turn north to join each other before Ghogali. These channels drain out groundwater from the shallow aquifers and thus reduce the availability of groundwater in the dug wells. As a result, majority of dug wells go dry during summer. The present work is aimed to delineate intertrappeans and fracture zones within the traps and Gondwana formation below the traps using vertical electrical sounding (VES) for the purpose of augmenting water supply from shallow aquifers in order to meet the ever increasing demand.
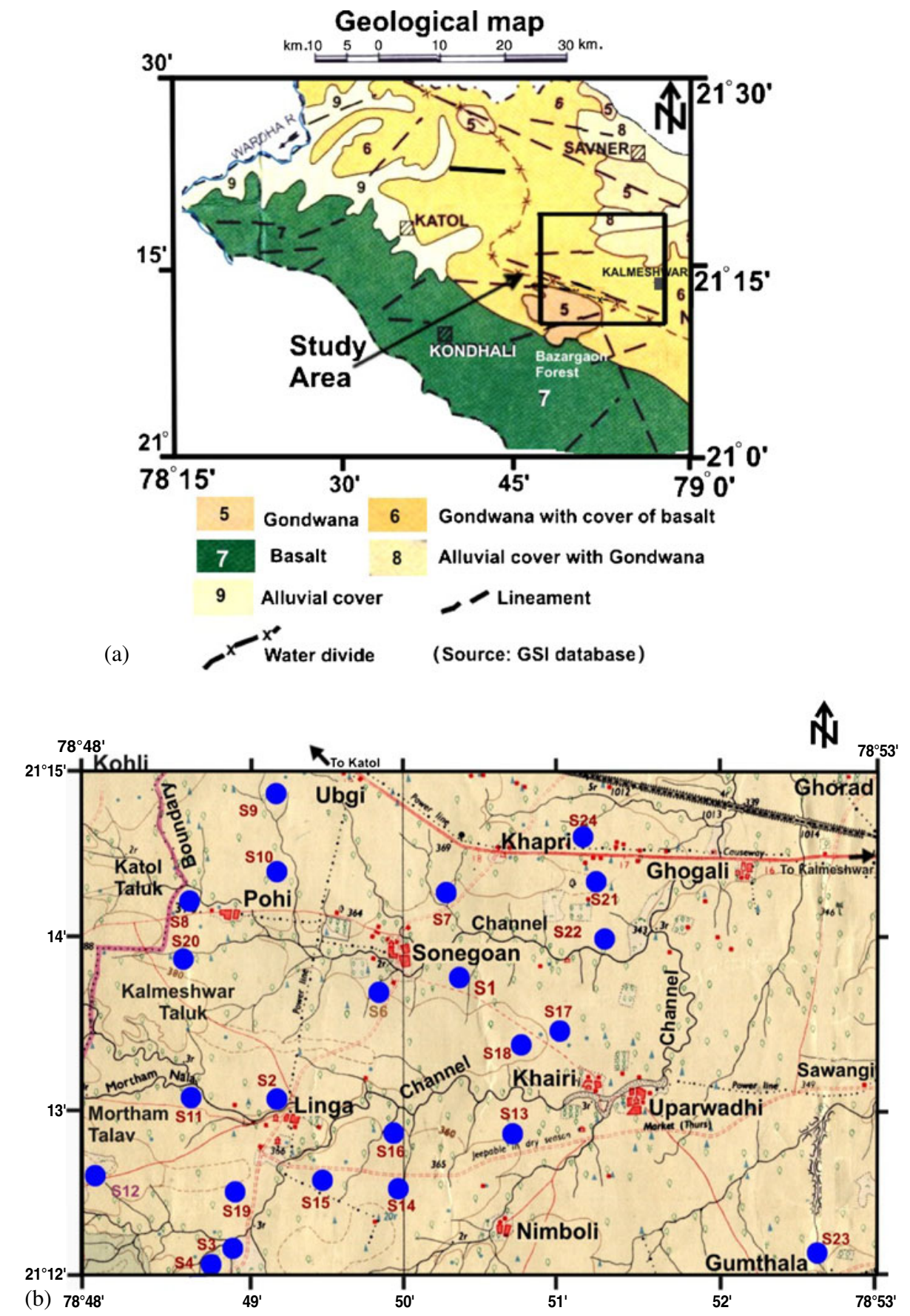

Figure 1. (a) Geology and location map of the study area (modified after District resource map, Nagpur, Maharastra, GSI, 2000). (b) Drainage pattern and location of VES sites represented by blue solid circles with sounding numbers (modified after SOI Toposheet no. $55 \mathrm{~K} / 6)$. 

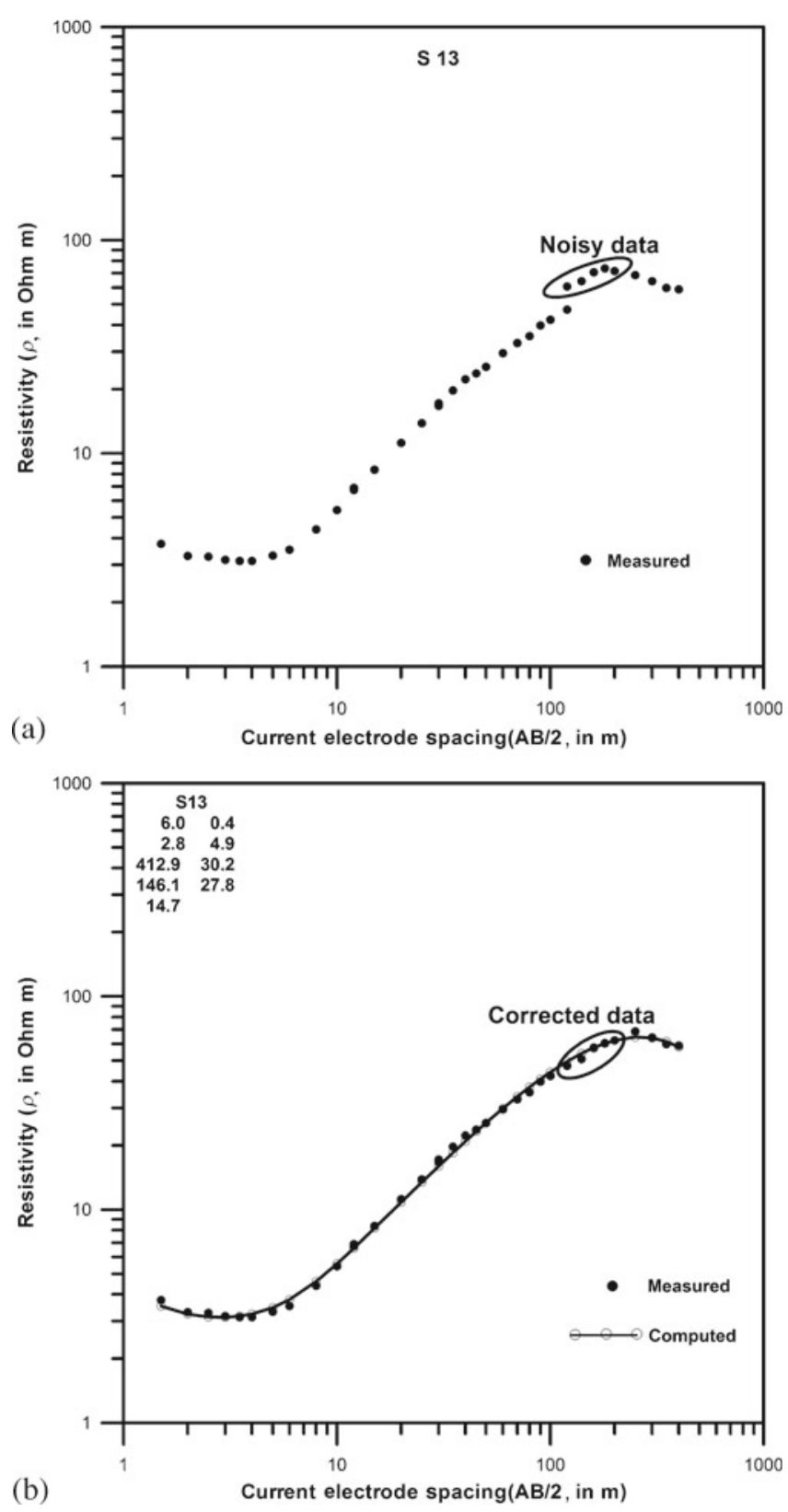

Figure 2. (a) Measured resistivity curve with noisy data. (b) Comparison of corrected measured resistivity curve with computed resistivity curve for S13.

\section{Vertical electrical soundings}

As mentioned in the earlier section, Deccan traps, unlike other hard rock terrains, consist of multiple layers of solidified lava flows and behave as a multilayered aquifer system similar to a sedimentary formation. In such a geological environ, VES is a suitable technique to map the depth distribution of litho units. Geological interpretation of these litho units leads to the delineation of aquifers at different depths. VES surveys using Schlumberger electrode configuration have been carried out by several workers in different parts of the Deccan traps. Bose and Ramkrishna (1978) have carried out surveys in the Deccan traps region in Sangli district of Maharashtra. Rao et al. (1983) have carried out integrated geophysical surveys consisting of VES and magnetic surveys for groundwater exploration in Deccan traps covered the GodavariPurana basin in Aurangabad district of Maharashtra. Murthy et al. (1986) have delineated Gondwana formation below the Deccan traps in Umrer, Bander, Kamathi and Katol troughs in Nagpur district. Kumar et al. (2010) have conducted an electrical resistivity survey to decipher potential groundwater zones in Deccan traps terrains falling under Aurangabad district. Muralidharan et al. (1994) have carried out deep VES for mapping depth of Gondwana sedimentary formations below the traps to select suitable sites of borewells in Jam river basin under Katol taluk. This basin lies towards the west of the present study area. Rai et al. (2011) have delineated aquifers in the form of intertrappeans concealed within the traps and Gondwana sedimentary formations below the traps in parts of Katol taluk of Nagpur.

\section{Data processing and interpretation}

A computer program 'RESIST' is used to process the measured apparent resistivity data and compute the inverse model of resistivity variation with depth (Vander Velpen and Sporry 1993). This program can accomplish three tasks: (i) smoothing of noisy field data, (ii) accurate computation of apparent resistivity models, and (iii) inversion of resistivity data. The output is the inverse resistivity model providing layer-wise distribution of resistivity value $\left(\rho_{n}\right)$ and thickness $(h)$ of the corresponding layer. Data smoothing for Schlumberger array includes single point correction and vertical curve branch shifting. The vertical curve branch shifting consists of a linear shift of one or more branches to correct misties between the branches. The correction of the misties is indicated by the amount of the difference between two apparent resisitivity observations with the same current electrode distance $(\mathrm{AB})$, but with different potential electrode separation (MN). An equal correction (on the logarithmic scale) is applied to all points of a selected branch. This leads to a shift in the apparent resistity level of that branch without changing its shape. To demonstrate an example of smoothing of noisy field data by vertical curve branch shifting, we consider five noisy data of measured apparent resistivity values for site S13 as shown in figure 2(a). In this case, two resistivity values, i.e., 47.2 and $60.6 \Omega \mathrm{m}$ are measured for the same $\mathrm{AB} / 2=$ $120 \mathrm{~m}$, but with different MN values. The amount 
of correction is $13.4 \Omega \mathrm{m}$. The five noisy data for $\mathrm{AB} / 2$ : $120,140,160,180$ and $200 \mathrm{~m}$ are 60.6, $64.2,70.7,73.8$ and $75.56 \Omega \mathrm{m}$, respectively. These data are corrected by subtracting $13.4 \Omega \mathrm{m}$ from the data. Corrected values are given in table 1 . Figure 2(b) shows the measured resistivity curve after smoothing the noisy five data.

For computation of inverse resistivity model, $\mathrm{AB} / 2$ values and the corresponding measured apparent resistivity is uploaded into an input file of the RESIST program. Based on the nature of measured resistivity curve, datasets of an initial inverse resistivity model which include numbers of layers, resistivity values and thickness of all the layers (except of last layer) are fed into the program. Based on the given input parameters of the initial inverse model, the program will compute apparent resistivity values for all $\mathrm{AB} / 2$ values. Then, computed resistivity curve based on the initial model parameters is compared with the measured resistivity curve. Comparison is displayed on the computer screen. In case of mismatch between these two sets of apparent resistivity values, the program will continue to make necessary changes in the numerical values of the parameters of the initial resistivity model till a good match between

Table 1. Comparison of measured and calculated apparent resistivity values for site S13.

\begin{tabular}{|c|c|c|c|}
\hline $\mathrm{AB} / 2$ & $\begin{array}{l}\text { Measured } \\
\text { apparent } \\
\text { resistivity }\end{array}$ & $\begin{array}{c}\text { Measured } \\
\text { apparent resistivity } \\
\text { (after correction) }\end{array}$ & $\begin{array}{c}\text { Calculated } \\
\text { apparent resistivity } \\
\text { values }\end{array}$ \\
\hline 1.5 & 3.8 & 3.8 & 3.5 \\
\hline 2 & 3.3 & 3.3 & 3.2 \\
\hline 2.5 & 3.3 & 3.3 & 3.1 \\
\hline 3 & 3.2 & 3.2 & 3.1 \\
\hline 3.5 & 3.1 & 3.1 & 3.2 \\
\hline 4 & 3.1 & 3.1 & 3.2 \\
\hline 5 & 3.3 & 3.3 & 3.5 \\
\hline 6 & 3.5 & 3.5 & 3.8 \\
\hline 8 & 4.4 & 4.4 & 4.6 \\
\hline 10 & 5.4 & 5.4 & 5.6 \\
\hline 12 & 6.9 & 6.9 & 6.6 \\
\hline 12 & 6.7 & 6.7 & 6.6 \\
\hline 15 & 8.4 & 8.4 & 8.2 \\
\hline 20 & 11.2 & 11.2 & 10.8 \\
\hline 25 & 13.9 & 13.9 & 13.4 \\
\hline 30 & 16.7 & 16.7 & 16.0 \\
\hline 30 & 17.2 & 17.2 & 16.0 \\
\hline 35 & 19.7 & 19.7 & 18.5 \\
\hline 40 & 22.3 & 22.3 & 20.9 \\
\hline 45 & 23.7 & 23.7 & 23.2 \\
\hline 50 & 25.5 & 25.5 & 25.5 \\
\hline 60 & 29.5 & 29.5 & 29.9 \\
\hline 70 & 32.9 & 32.9 & 33.9 \\
\hline 80 & 35.5 & 35.5 & 37.6 \\
\hline 90 & 39.8 & 39.8 & 41.0 \\
\hline 100 & 42.4 & 42.4 & 44.2 \\
\hline 120 & 47.2 & 47.2 & 49.6 \\
\hline 120 & $60.6^{*}$ & $47.2^{\#}$ & - \\
\hline 140 & $64.2^{*}$ & $50.8^{\#}$ & 54.0 \\
\hline 160 & $70.7^{*}$ & $57.3^{\#}$ & 57.5 \\
\hline 180 & $73.8^{*}$ & $60.4^{\#}$ & 60.2 \\
\hline 200 & $75.6^{*}$ & $62.1^{\#}$ & 62.2 \\
\hline 250 & 68.6 & 68.6 & 64.5 \\
\hline 300 & 64.3 & 64.3 & 63.9 \\
\hline 350 & 59.7 & 59.7 & 61.4 \\
\hline 400 & 58.8 & 58.8 & 57.9 \\
\hline
\end{tabular}

*: Noisy data; \#: corrected data. 
measured and computed values of apparent resistivity is achieved. This process is accomplished by iteration procedures. The resistivity model for which good agreement between computed and measured apparent resistivity values is achieved in the desired inverse resistivity model. Table 1 presents a comparison between measured and computed apparent resistivity values. Figure 2(b) presents a graphical illustration of the comparison along with the corresponding inverse resistivity models.

Graphical illustrations of comparison between measured apparent resistivity values represented by small solid circles and computed apparent resistivity values represented by open circles and connected by line curve for VES sites under administrative jurisdiction of Pohi, Sonegaon, Khapri,
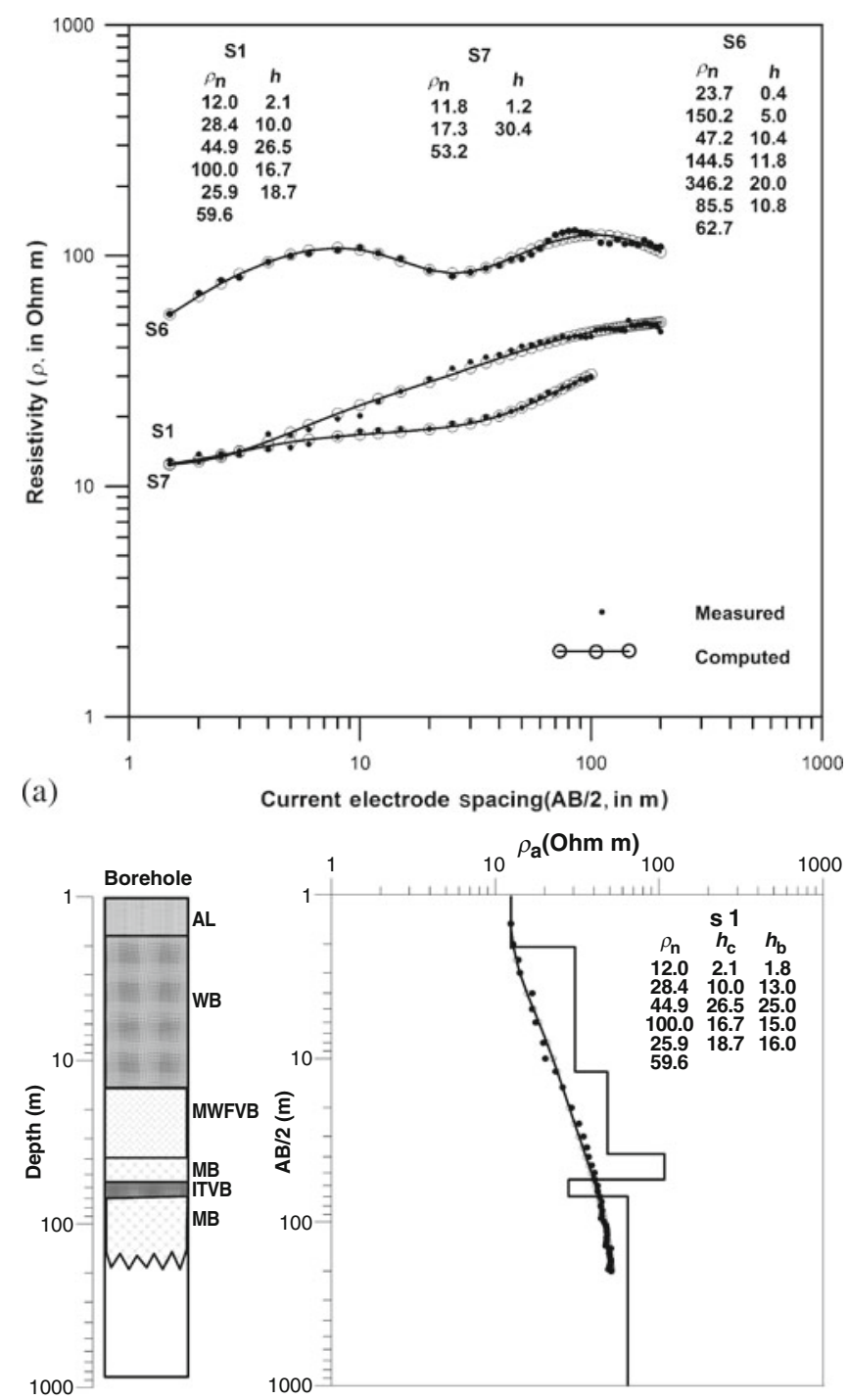

(b)

Figure 3. (a) Comparison of measured resistivity curve with computed resistivity curve for S1, S6 and S7 sites. (b) Comparison of computed thicknesses of layers $\left(h_{\mathrm{c})}\right.$ with the thicknesses obtained from borewell $\left(h_{\mathrm{b}}\right)$ at site S1.
Linga, Khairi and Gumthala villages are presented in figures 3-8. Both sets of results are found to be in good agreement with each other. The corresponding computed inverse resistivity models for each site are also given in the inset of the figures.

The next step is the interpretation of inverse resistivity models in terms of sub-surface litho units to identify potential aquifers above, within and below the traps. Based on the electrical surveys carried out in parts of Nagpur, Amaravati, Akola and Jalgaon districts of Maharashtra, the following resistivity values for the different litho units of Deccan traps terrain are suggested by the Central Ground Water Board of India (source: website of CGWB).
Alluvial, Black cotton
soil (AL) and
bole bed (BB): 5-10 $\Omega \mathrm{m}$
Lameta beds (LB): $<15 \Omega \mathrm{m}$
Weathered/fractured/vesicular
basalt saturated
with water (WFVB): 20-40 $\Omega \mathrm{m}$
Moderately weathered/fractured/vesicular
basalt saturated
with water (MWFVB): 40-70 $\Omega \mathrm{m}$
Massive basalt (MB): $<70 \Omega \mathrm{m}$
Water-saturated Gondwana
formation (WGS): $<50 \Omega \mathrm{m}$
Gondwana formation
without water (GS): $>50 \Omega \mathrm{m}$

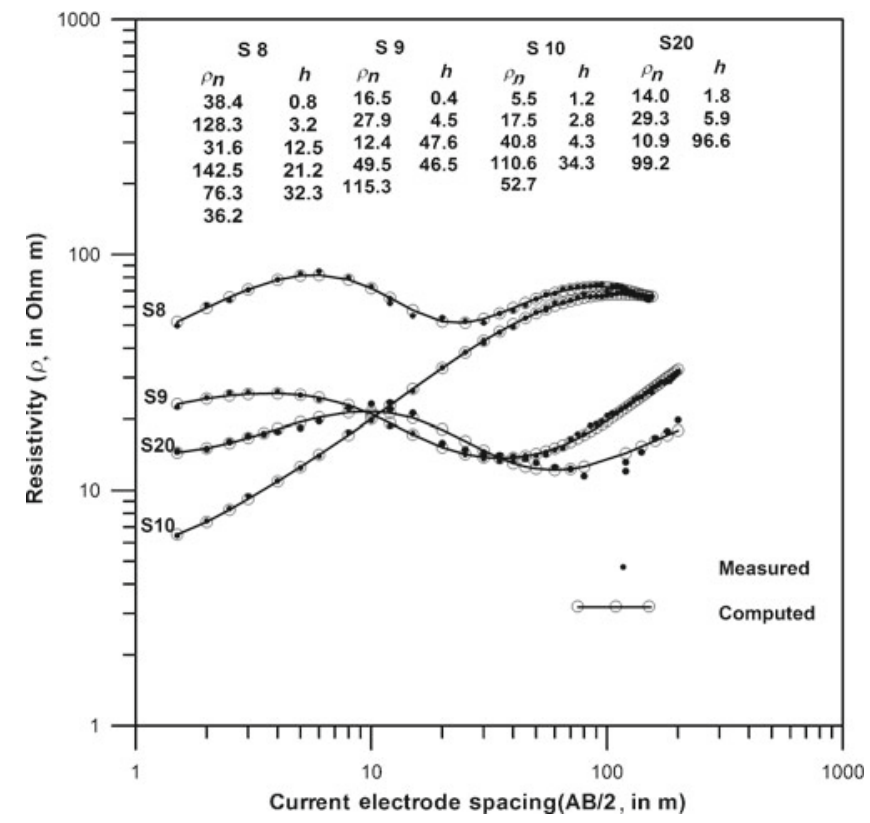

Figure 4. Comparison of measured resistivity curve with computed resistivity curve for S8, S9, S10 and S20 sites, Pohi. 


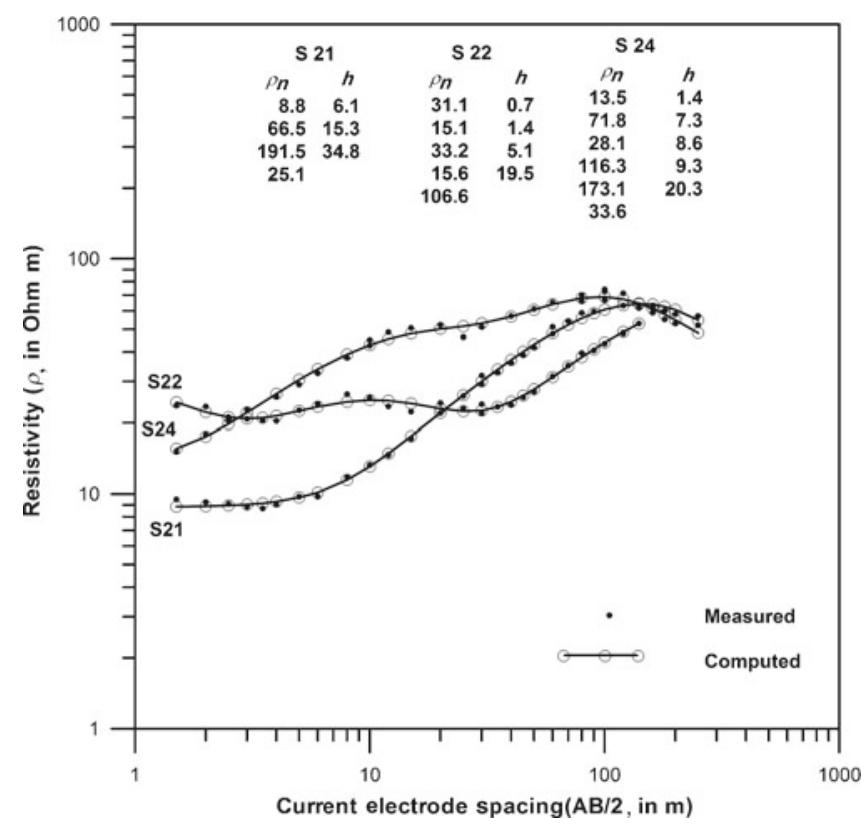

Figure 5. Comparison of measured resistivity curve with computed resistivity curve for S21, S22 and S24 sites, Khapri.

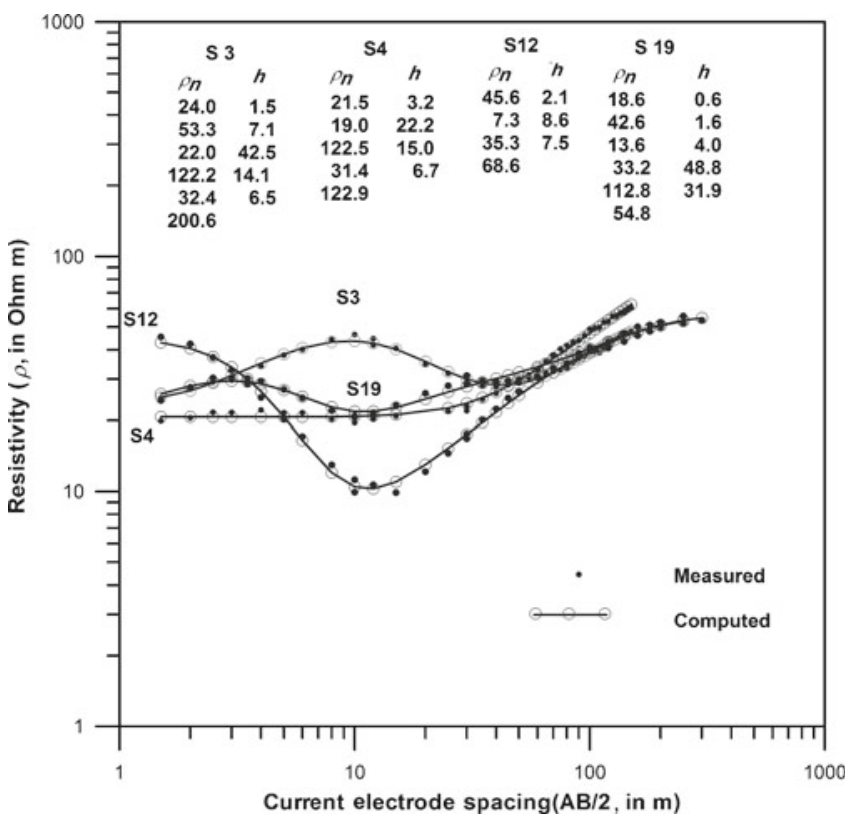

Figure 6. Comparison of measured resistivity curve with computed resistivity curve for S3, S4, S12 and S19 sites, Linga.

More or less, same values of resistivity are considered for the interpretation of sounding results in terms of geological formation to identify aquifers within and below the traps. In this paper, WFVB and the MWFVB are used to refer unconfined aquifers above the traps. Resistivity value of the water-saturated intertrappeans together with vesicular basalt unit (ITVB) is represented by the resistivity value of the WFVB. Similarly,

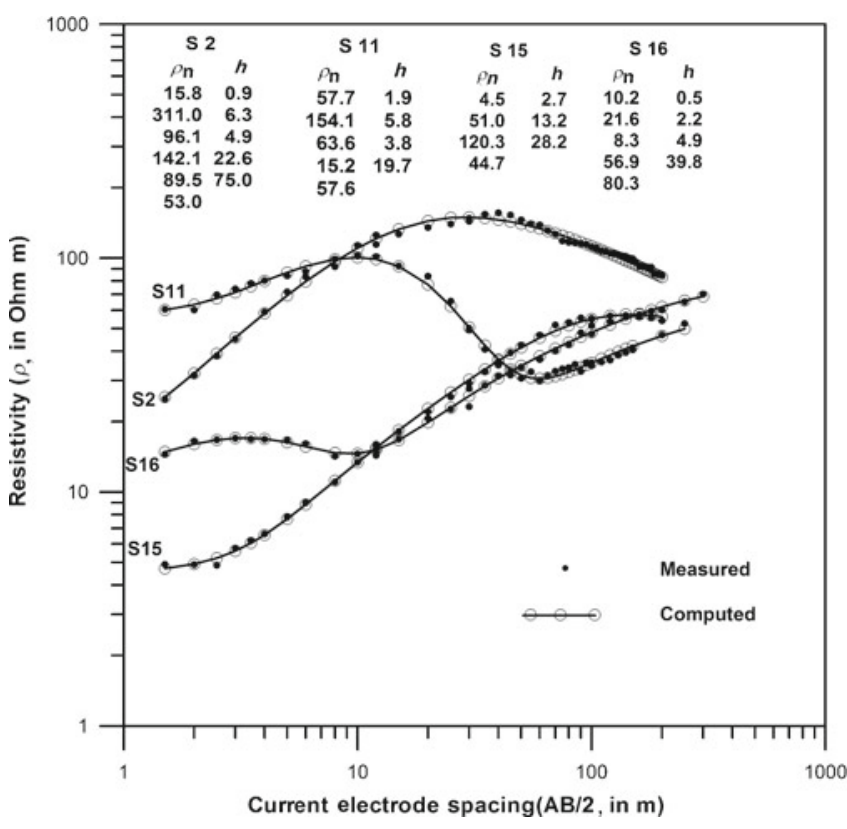

Figure 7. Comparison of measured resistivity curve with computed resistivity curve for S2, S11, S15 and S16 sites, Linga.

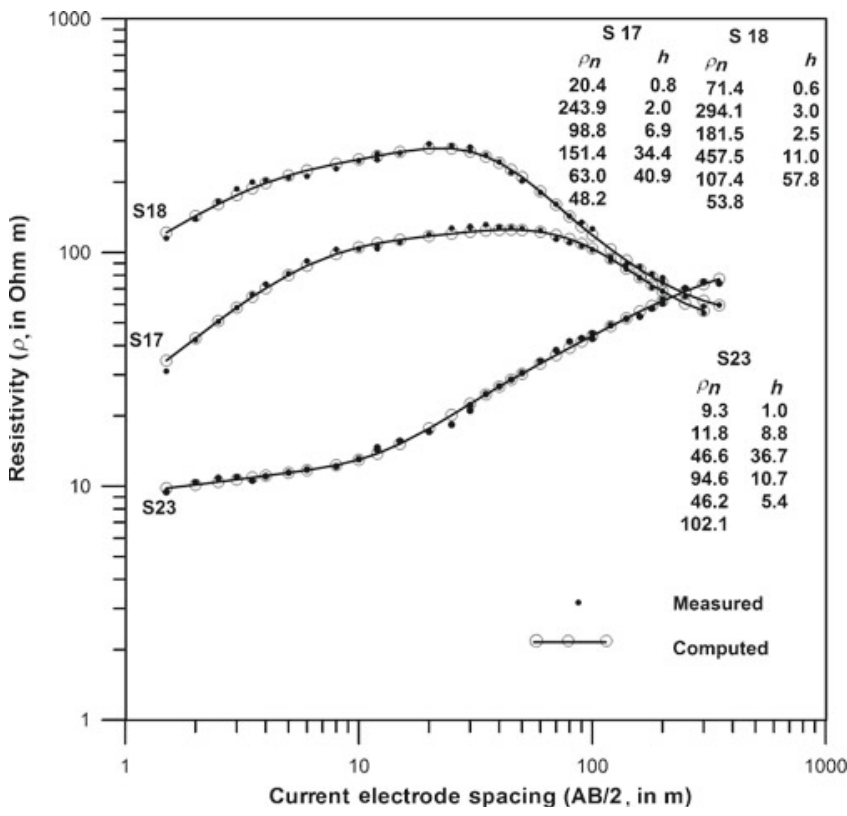

Figure 8. Comparison of measured resistivity curve with computed resistivity curve for S17 and S18 sites in Khairi and S23 site in Gumthala.

resistivity value of the moderately saturated intertrappeans together with vesicular basalt (MITVB) unit is represented by the resistivity value for MWFVB. Our experience based on borewells drilled at two VES sites in the adjoining Katol taluk suggests that the geological formations including Gondwana with resistivity value in the 
range of $15-30 \Omega \mathrm{m}$ provide good yield and is considered a good aquifer. Yield of geological formation with resistivity values in the range of 30 $40 \Omega \mathrm{m}$ is moderate (Rai et al. 2011). This observation is taken into consideration for interpretation of results. The VES surveys were carried out at different times. The survey sites are numbered accordingly. Geological interpretations of resistivity models for village-wise sounding sites are described below.

It is worth mentioning that the results presented in figures 3-8 are also summarized in table 2 along with some additional information, which includes AB length, Root Mean Square (RMS) error, depth of litho units and possible depth of likely occurrence of aquifers. Depth is measured from the ground surface. The depth of the last litho unit represents depth of investigation at that site. It is evident from the table that the depth of investigation for each site is well within the range of 0.1 to 0.3 times the spread lengths of the profile (Bernard 2003). The next section presents geological interpretation of the inverse resistivity models for the VES sites identified village-wise.

\subsection{Sonegaon (S1, S6, S7)}

The VES sites S1, S6 and S7 lie in Sonegaon village. Inverse resistivity models for these sites are given in the inset of figure 3(a). Interpreted results for S1 site indicate $2.1-\mathrm{m}$ thick alluvium overlying a $10-\mathrm{m}$ thick weathered formation $(28.4 \Omega \mathrm{m})$, which could be a source of groundwater. Weathered formation is underlain by $26.5-\mathrm{m}$ thick MWFVB layer having $44.9 \Omega \mathrm{m}$ resistivity. An ITVB layer $(25.9 \Omega \mathrm{m})$ of 18.7-m thickness is also indicated between MB layers with 100 and $59.6 \Omega \mathrm{m}$ resistivity, respectively. This layer could be another source of groundwater at this site. Though the resistivity value of the bottom layer is less than $70 \Omega \mathrm{m}$ assigned for $\mathrm{MB}$, the ascending trend of the resistivity curve indicates that this formation is MB. For this site, AB is $400 \mathrm{~m}$ and the depth of investigation is $74 \mathrm{~m}$, which is $<0.3$ of the AB. Similar is the case for S6 and $\mathrm{S} 7$ sites. A borewell was drilled at S1 site to verify the modelling results. A comparison between thicknesses of litho units obtained from modelling $\left(h_{\mathrm{c}}\right)$ and borewell $\left(h_{\mathrm{b}}\right)$ is presented in figure $3(\mathrm{~b})$. Both results are found in good agreement, which validates the interpreted stratigraphic sequence.

In case of S6 site, only one layer of MITVB $(47.2 \Omega \mathrm{m})$ of $10.4 \mathrm{~m}$ thickness is indicated between two MB layers of 5.0 and $42.6 \mathrm{~m}$ thicknesses, respectively. The formation at $58.4 \mathrm{~m}$ depth with $62.7 \Omega \mathrm{m}$ resistivity value could be dry Gondwana formation. This site may not be favourable for groundwater exploration. The profile length for S7 site is only $200 \mathrm{~m}$, which is half of the profile at site S1. The corresponding resistivity model presents only three layers. The second layer $(17.3 \Omega \mathrm{m})$ of $30.4-\mathrm{m}$ thickness appears to be a water-bearing layer. This layer is underlain by MWFVB (53.2 $\Omega \mathrm{m})$ layer. For this site, depth of investigation is only $31.6 \mathrm{~m}$.

\subsection{Pohi (S8, S9, S10, S20)}

Resistivity models for S8, S9, S10 and S20 are given in figure 4 . The resistivity model for $\mathrm{S} 8$ site indicates an ITVB layer $(31.2 \Omega \mathrm{m})$ of $12.5 \mathrm{~m}$ thickness between two MB layers of 3.2 and $53.5 \mathrm{~m}$ thicknesses. Here, Gondwana formation $(32.2 \Omega \mathrm{m})$ is at $70 \mathrm{~m}$ depth. Resistivity model for S9 site shows a 47.6-m thick water-saturated layer of weathered basalt (WB) $(12.5 \Omega \mathrm{m})$, which is a potential source of groundwater. This layer is underlain by $46.5-\mathrm{m}$ thick MWFVB layer $(49.5 \Omega \mathrm{m})$. At this site, presence of $\mathrm{MB}(115.3 \Omega \mathrm{m})$ is indicated at $99 \mathrm{~m}$ depth. At S10 site, a 2.8-m thick layer of WB $(17.5 \Omega \mathrm{m})$ is underlain by $4.3-\mathrm{m}$ thick layer of MWFVB $(40.8 \Omega \mathrm{m})$, which is followed by an MB layer $(110.6 \Omega \mathrm{m})$ of $34.3 \mathrm{~m}$ thickness, and dry Gondwana formation (52.7) at $42 \mathrm{~m}$ depth. This site is not favourable for groundwater exploration. The S20 site is located in a valley adjacent to Mordham Talav (reservoir) within $<1 \mathrm{~km}$ distance in the south. The resistivity model for this site indicates the presence of $\sim 96-\mathrm{m}$ thick water-saturated formation $(10.9 \Omega \mathrm{m})$, which is underlain by $\mathrm{MB}$ $(99.2 \Omega \mathrm{m})$ layer. Interpreted results suggest that sites S9 and S20 are most suitable for groundwater exploration.

\subsection{Khapri (S21, S22, S24)}

Resistivity models for S21, S22 and S24 sites in Khapri village are presented in figure 5 . The resistivity model for S21 site indicates the presence of $6.1-\mathrm{m}$ thick layer of soil and water-saturated WB $(8.8 \Omega \mathrm{m})$. This is underlain by $15.3-\mathrm{m}$ thick layer of MWFVB $(66.5 \Omega \mathrm{m})$. Below this layer is 34.8$\mathrm{m}$ thick layer of MB $(191.5 \Omega \mathrm{m})$. Gondwana formation $(25.1 \Omega \mathrm{m})$ is indicated at $56.2 \mathrm{~m}$ depth. Resistivity model for S22 site suggests the presence of alluvial (15.1-31.1 $\Omega \mathrm{m})$, WB (33.2) and WFVB layers $(15.6 \Omega \mathrm{m})$ up to $26.6 \mathrm{~m}$ depth. This composite layer forms good unconfined aquifer. Below it lies MB $(106.6 \Omega \mathrm{m})$ at $26.6 \mathrm{~m}$ depth. Because of small spread length $(280 \mathrm{~m})$, the depth of investigation is confined to only $26.7 \mathrm{~m}$. The model for S24 sites shows the presence of 8.6-m thick layer of ITVB $(28.1 \Omega \mathrm{m})$ sandwiched between 7.3 and 29.6-m thick MB layers. The Gondwana formation $(33.6 \Omega \mathrm{m})$ is at $47 \mathrm{~m}$ depth which together with ITVB unit can be explored for groundwater. 


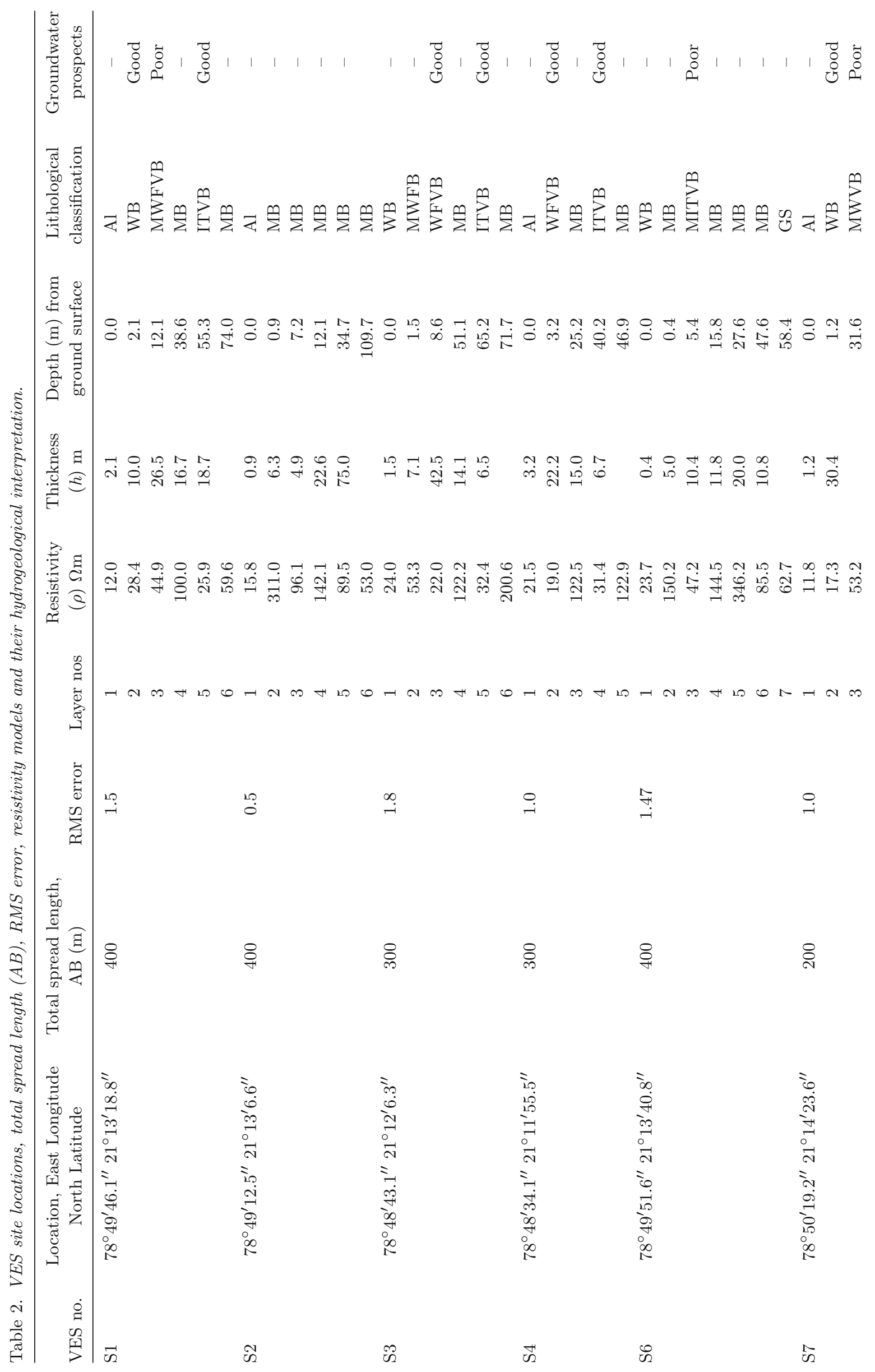




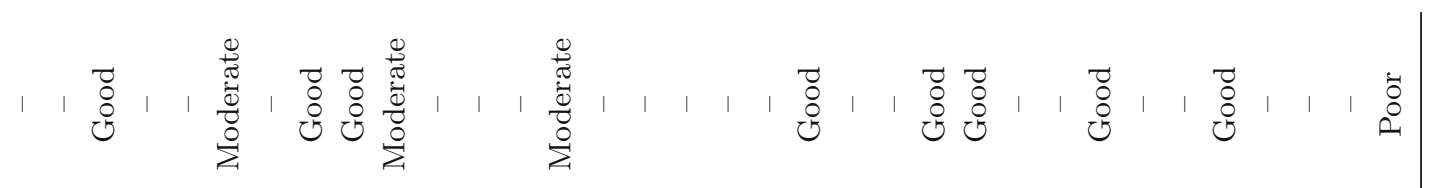

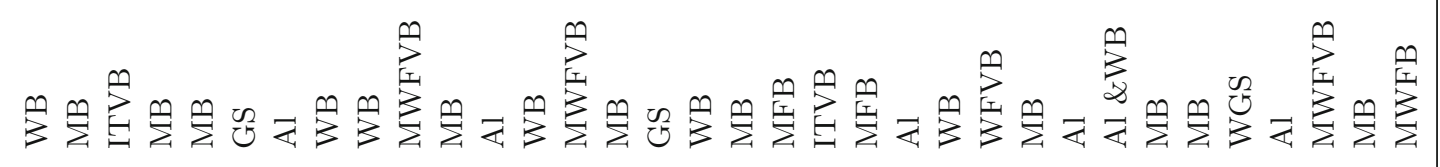

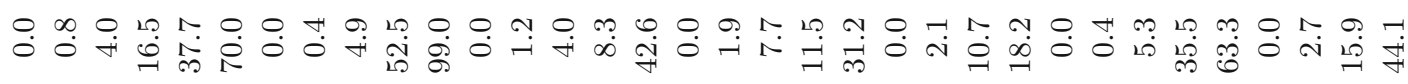

舟

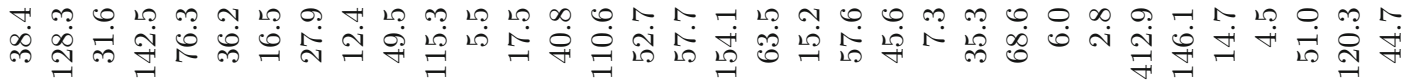

$\pi$ h

$\stackrel{-1}{\Im}$

$\stackrel{\sim}{\sim}$

ז̊.

$\stackrel{\infty}{-}$

$\stackrel{-1}{\sim} \stackrel{\infty}{\sim}$

$\stackrel{\Re}{-}$

ฉి

앙

아

8

온

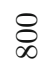

앙

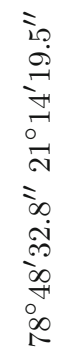

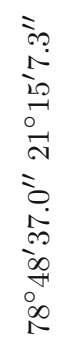

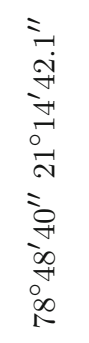

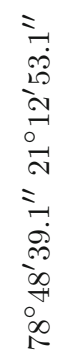

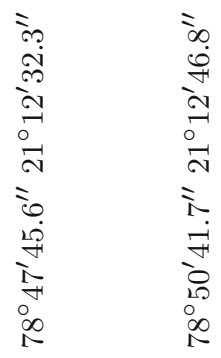

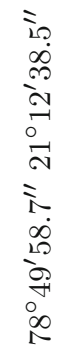

$\infty$

ช

$\underset{1}{\stackrel{1}{1}}$

큼

$\stackrel{\sim}{\mathscr{N}}$

$\stackrel{\infty}{\pi}$

$\stackrel{201}{12}$ 


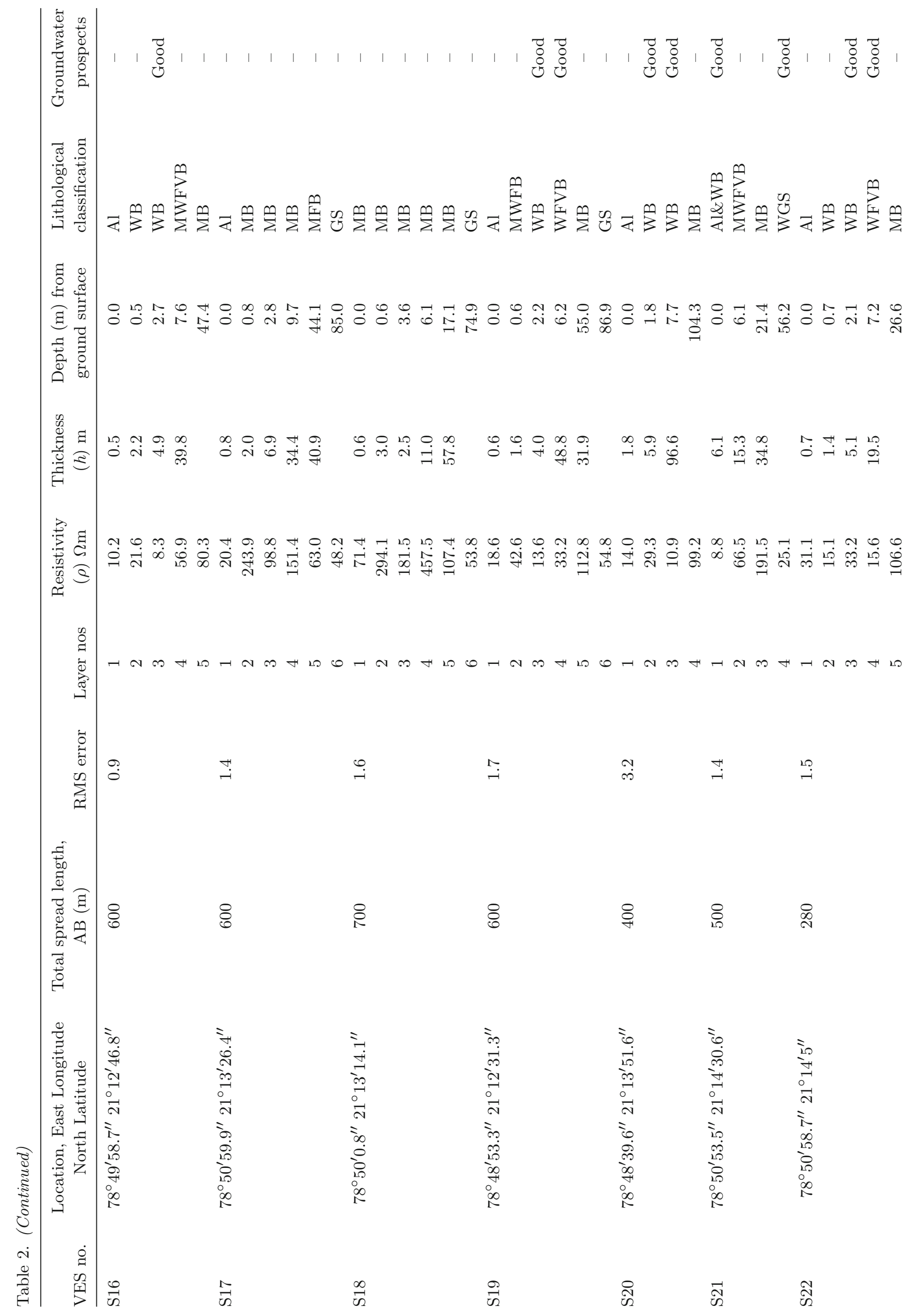




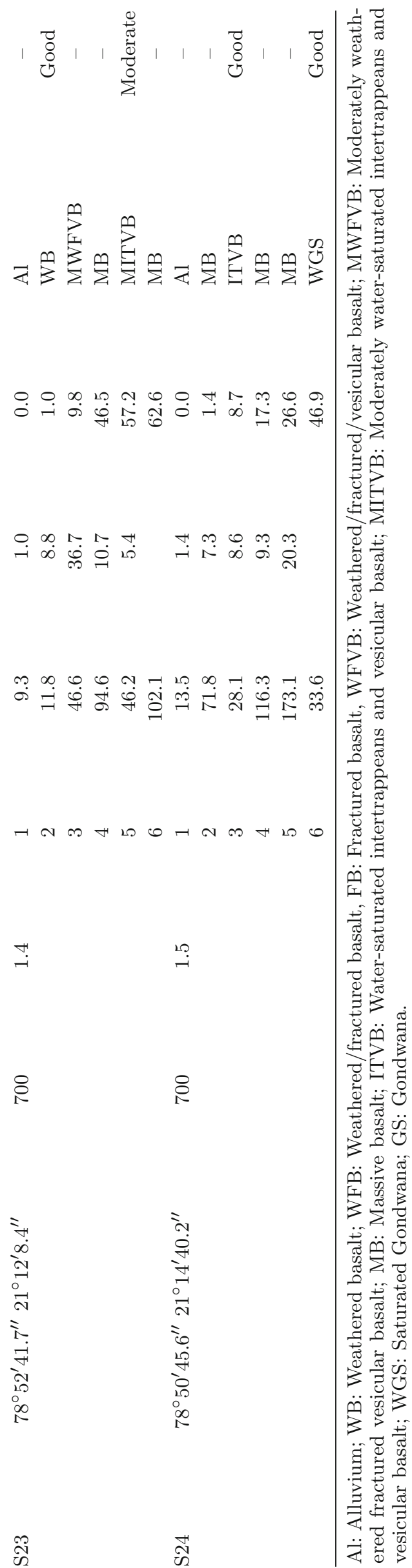

3.4 Linga (S2, S3, S4, S11, S12, S15, S16, S19)

VES sites S2, S3, S4, S11, S12, S15, S16 and S19 belong to Linga village. Resistivity models for S3, S4, S12 and S19 sites, which are in close vicinity are presented in figure 6 , while the models for remaining sites S2, S11, S15 and S16 are presented in figure 7 . Interpreted stratigraphic sequence for S3 sounding indicates the presence of $42.5-\mathrm{m}$ thick WFVB $(22 \Omega \mathrm{m})$ underlain by a MB $(122.2 \Omega \mathrm{m})$ layer of $14.1 \mathrm{~m}$ thickness. In addition to that, another water-bearing ITVB $(32.4 \Omega \mathrm{m})$ of $6.5 \mathrm{~m}$ thickness is indicated between two MB layers. This site is favourable for groundwater exploration from these two water-bearing stratum. At S4 site, two water-saturated layers are indicated. The first one is WB $(19 \Omega \mathrm{m})$ of $22.2 \mathrm{~m}$ thickness, and another one is ITVB $(31.4 \Omega \mathrm{m})$ of $6.7 \mathrm{~m}$ thickness. At S12 site, a layer of WFVB layer $(7.3-35.3 \Omega \mathrm{m})$ of $16.1 \mathrm{~m}$ is identified as a source of groundwater. The ascending trend of resistivity curve at its ending edge suggests that the underlying formation characterized by $68.6 \Omega \mathrm{m}$ resistivity value is MB. Resistivity model for S19 site suggests a $52.8-\mathrm{m}$ thick layer of WFVB (13.6-33.2 $\Omega \mathrm{m})$, which is underlain by $31.9-\mathrm{m}$ thick layer of MB $(112 \Omega \mathrm{m})$. At this site, dry Gondwana formation $(54.8 \Omega \mathrm{m})$ appears to be at $87 \mathrm{~m}$ depth.

Resistivity model of S2 site indicates a 109.7-m thick MB layer (89.5-311 $\Omega \mathrm{m}$ ) overlying a dry Gondwana formation $(53.0 \Omega \mathrm{m})$. Based on the interpretation of the data, this site may be unfavourable for exploration. In case of S11 site, a 19.7-m thick water-saturated layer of ITVB $(15.2 \Omega \mathrm{m})$ is indicated, which appears to be potential source of groundwater at this site. Though the geological formation underlying ITVB layer is characterized by $57.6 \Omega \mathrm{m}$ resistivity value which is less than $70 \Omega \mathrm{m}$ assigned to $\mathrm{MB}$, the ascending trend of the resistivity curve towards its end portion suggests that the formation is MB. Exposed MB can be seen in the areas of S2 and S11 sites. Resistivity model of S15 indicates moderately saturated Gondwana formation $(44.7 \Omega \mathrm{m})$ below $28.2-\mathrm{m}$ thick layer of MB $(120.3 \Omega \mathrm{m})$. This site may not be favourable for groundwater exploration. In case of S16, a 4.9-m thick water-saturated layer of WB is underlain by a 39.8-m thick layer of MWFVB $(57 \Omega \mathrm{m})$ followed by $\mathrm{MB}(80.3 \Omega \mathrm{m})$.

\subsection{Khairi (S13, S17, S18)}

Sites S13, S17 and S18 lie in Khairi village. Resistivity models for S13 are presented in figure 2(b) and for S17 and S18 sites are presented in figure 8. The model for S13 indicates an alluvial layer (2.8$6 \Omega \mathrm{m})$ of $5.3 \mathrm{~m}$ thickness overlying a $58-\mathrm{m}$ thick 
Table 3. Quality analysis of groundwater from a dug well (near S14), Linga village.

\begin{tabular}{|c|c|c|c|c|c|c|}
\hline Site & $\begin{array}{l}\text { Conductivity } \\
\quad(\mu \text { mhos })\end{array}$ & $\begin{array}{l}\text { Fluoride } \\
(\mathrm{mg} / \mathrm{l})\end{array}$ & $\begin{array}{l}\text { Chloride } \\
(\mathrm{mg} / \mathrm{l})\end{array}$ & $\begin{array}{l}\text { Sulphate } \\
(\mathrm{mg} / \mathrm{l})\end{array}$ & $\begin{array}{l}\text { Nitrate } \\
(\mathrm{mg} / \mathrm{l})\end{array}$ & $\begin{array}{l}\mathrm{TDS} \\
(\mathrm{mg} / \mathrm{l})\end{array}$ \\
\hline $\begin{array}{l}\text { Acceptable value WHO } \\
\text { specification }\end{array}$ & 1500 & $0.6-1.5$ & 250 & 200 & 45 & 500 \\
\hline Analysed values & 839 & 1.74 & 106.7 & 0.19 & 4.1 & 544 \\
\hline
\end{tabular}

MB layer (412.9-146.1 $\Omega \mathrm{m})$. At this site, Gondwana formation $(14.7 \Omega \mathrm{m})$ appears to lie at $63.3 \mathrm{~m}$ depth. This site is suitable for groundwater exploration from composite layers of $\mathrm{Al}$ and WB stratum at shallower depth and Gondwana formation below the traps at deeper level. The resistivity model for S17 indicates the presence of a 43.3-m thick MB (98.8-243.9 $\Omega \mathrm{m})$ followed by $40.9-\mathrm{m}$ thick layer of moderately fractured basalt $(63 \Omega \mathrm{m})$. At this site, moderately saturated Gondwana formation $(48.2 \Omega \mathrm{m})$ appears to be at $85 \mathrm{~m}$ depth. Resistivity model for S18 suggests the presence of dry Gondwana formation $(53.8 \Omega \mathrm{m})$ below 74.9-m thick layer of MB. Based on the analysis of the resistivity models of S17 and S18, these two sites do not show presence of any potential source of groundwater amenable for groundwater exploration.

\subsection{Gumthala (S23)}

The VES site S23 lies in Gumthala village. The resistivity model for this site is also presented in figure 8. This model indicates $8.8-\mathrm{m}$ thick layer of water-saturated weathered formation $(11.8 \Omega \mathrm{m})$ followed by $36.7-\mathrm{m}$ thick layer of MWFVB $(46.6 \Omega \mathrm{m})$. This composite layer of weathered formation and MWFVB forms a potential source of groundwater. Another 5.4-m thick layer of MITVB $(46.2 \Omega \mathrm{m})$ at $57 \mathrm{~m}$ depth is shown between two MB layers with 94.6 and $102 \Omega \mathrm{m}$ resistivity values, respectively.

\subsection{Water quality}

In this region, similar to any other rural area of the country, groundwater from dug wells is directly used for drinking. Therefore, analysis of groundwater quality was essential to test its suitability for drinking. Groundwater sample from a dug well located in Linga village was collected in sterilized good quality plastic bottle and was sealed in polythene cover. The sample was analysed in the laboratory at NGRI. The result, presented in table 3 , indicates that the values of physical parameters and chemical constituents are within the permissible limit of potability as per the WHO specification.

\section{Conclusion}

Computed inverse resistivity models suggest presence of potential groundwater zones at many VES sites in the form of weathered mantle above the traps, intertrappeans and fractures concealed within the traps and Gondwana sedimentary formation below the traps at different depths. Based on the computed and observed values of resistivity and interpretation of the data, perhaps the VES sites S2, S6, S10, S15, S17 and S18 may not be potential sources of groundwater. Lithological sequence obtained from the computed inverse resisitivity model for site $\mathrm{S} 1$ is validated by borewell drilling. Depth of occurrences of the aquifers is given in table 2. According to the WHO specification, groundwater from a dug well near Linga is found to be potable. Substantial quantities of groundwater from shallower aquifers which are the main source of groundwater supply to dug wells are being drained out through channels. Therefore, check dams across the channels at appropriate locations should be constructed to increase the availability of groundwater in dug wells.

\section{Acknowledgements}

The authors thank the Director, CSIR - NGRI for according permission to publish this work. They also thank Dr R Rangarajan for the analysis of groundwater quality. They are grateful to the reviewers for their valuable suggestions to improve the quality of the paper.

\section{References}

Bernard J 2003 Short note on the depth of investigation of electrical methods; p. 8 (Source: Google search).

Bose R N and Ramkrishna T S 1978 Electrical resistivity surveys for groundwater in the Deccan trap country of Sangli district, Maharashtra; J. Hydrol. 38 209-221.

CGWB 2003 Groundwater resources and development potential of Nagpur district, Maharashtra; Report, Central Region, Nagpur, 74p.

Chakravarthi V, Shankar G B K, Muralidharan D, Harinarayana T and Sundarajan N 2007 An integrated geophysical approach for imaging subbasalt sedimentary basins: Case study of Jam River basin; Geophysics 72(6) B141-147. 
Kumar D, Rao V A, Nagaiah E, Raju P K, Mallesh D, Ahmeduddin M and Ahmed S 2010 Integrated geophysical study to decipher potential groundwater and zeolite-bearing zones in Deccan traps; Curr. Sci. 98(6) 803-814.

Mehta M 1989 Ground water resources and development potential of Nagpur district, Maharashtra; CGWB, $434 / \mathrm{DR} / 12 / 89$.

Muralidharan D, Deshmukh S D, Rangarajan R, Krishna V S R and Athavale R N 1994 Deep resistivity surveys for delineation of Deccan trap-Gondwana contact and selection of water well sites in Jam River basin; Tech. report no. NGRI-94-GW-153, 63p.

Murthy B G K, Raghunath Rao K and Punekar D V 1986 Report on the geophysical investigations for delineating
Gondwana below traps in Umrer, Bander, Kamathi and Katol troughs in Nagpur district under "Deep Geology Project" (field session 1984-1985).

Rai S N, Thiagarajan S and Ratnakumari Y 2011 Exploration of groundwater in the basaltic Deccan traps terrain in Katol taluk, Nagpur district, India; Curr. Sci. 101(9) 1198-1205.

Rao T G, Athavale R N, Singh V S, Muralidharan D and Murthy N N 1983 Geophysical exploration for groundwater in Deccan traps of Godavari-Purna basin, Maharashtra; NGRI technical report no. GH 18-GP10.

Vander Velpen B P A and Sporry R J 1993 RESIST - a computer program to process resisitivity sounding data on PC compatibles; Comput. Geosci. 19(5) 691-703. 